\title{
Research on the Reform Method of Civil Engineering Graphics Course
}

\author{
Nan Zhang ${ }^{1, a^{*}}$, Xin Chen ${ }^{2}$, and Xin Wang ${ }^{3}$ \\ ${ }^{1}$ Shenyang Jianzhu University, School of science, Shenyang, China \\ ${ }^{2}$ Shenyang Jianzhu University, Library, Shenyang, China \\ ${ }^{3}$ Shenyang Jianzhu University, School of information and control engineering, Shenyang, China \\ alzyl068052@126.com \\ *The corresponding author
}

Keywords: Engineering graphics; Teaching method; Reform; Examination

\begin{abstract}
The engineering course is a compulsory basic course for the students of civil engineering. This paper starts from the analysis of the teaching status of civil engineering graphics course, in view of the characteristics of each professional engineering course, and aims at the improvement of the teaching method and the examination reform, so as to stimulate students' enthusiasm for learning, enhance learning initiative, cultivate innovative spirit, suitable for social needs of highquality talent, which provides ideas and attempts for engineering courses to play a greater role in higher education.
\end{abstract}

\section{Introduction}

The Engineering graphics course is to cultivate students' ability of graphic thinking, to cultivate students' ability of drawing, ability of mapping and train the necessary skills of students' engineering graphics, lay the foundation of the other follow-up professional courses and work after graduation. It is an integrated curriculum that integrates knowledge, practice, quality and ability. It has an irreplaceable role in cultivating students' comprehensive qualities and innovative ability. Engineering Graphics course is mainly studied by using the projection method to illustrate spatial geometric problems. Through the study of this course, students have the ability to map and graph space geometric problems, lay the foundation for the follow-up courses. This course has a distinctive feature of the use of the map to cultivate logical thinking and imagination, that is, in the process of learning, must always be on the plane projection and imagination of space geometric elements combined, this combination is how to express the three dimensional object on the two dimensional plane. And the cultivation of the ability of transform can only be done step by step.

The main problems of traditional engineering graphics in teaching and examination.

Engineering graphics course is a new course for college students, its main task is to cultivate the students' spatial analysis ability, graphic thinking ability, mapping ability and drawing ability, lay a solid foundation for the subsequent professional courses learning and future work. Some college students did not adapt to the university's learning style, although very hard, but still in the study of engineering science this course, because the original did not come into contact with the relevant aspects of training, it is not suited; some students, although the beginning of college life, but also Immersed in the joy of the success of the college entrance examination, there is no thought to learn; there are some students, usually do not study hard, only the final exam before the surprise [1]. For the students of architectural institutions, the future work requires a lot of drawing and design work, so master the course of the degree of knowledge directly affect the follow-up of professional courses, therefore, we must lay the foundation. In order to improve the enthusiasm of students to learn, emphasize in the teaching methods and test links, so that students recognize the importance of this course to enhance students to learn the subjective sense of the curriculum to improve the effectiveness of teaching and student learning initiative [2].

The geometry of the drawing is based on the projection theory, the projection of point, line, plane, and object; the relative position between point and line, line and line, line and plane, plane and 
plane; the intersection of plane and object, the three views of composite object, focusing on training students image thinking ability and spatial analysis ability. Through years of teaching practice, we found that "descriptive geometry" is difficult for teacher to teach, and is difficult for students to understand [3]. Many students in the first semester have to face multidisciplinary repair or even drop out in the case of traditional "one set of success or failure" type of final examination. A paper involved in the limited knowledge, not objective, fair and true reflection of the student's learning situation [4]. Because of the solid knowledge of math knowledge, directly affects the study of specialized courses in the future, the curriculum design, graduation design and even later work, therefore, it is necessary to change the traditional teaching ideas and construct the course system of engineering graphics for students of architectural colleges.

\section{Method}

Identify Educational Goals and Establish New Curriculum Systems. The paper puts forward the goal of cultivating students' four abilities: cultivating students' ability of spatial imagination and spatial thinking; cultivating students' ability to turn spatial thinking into graphics; cultivating students' ability to transform graphics into models; cultivating students' ability to draw graphics. The establishment of a new curriculum system, the engineering graphics course teaching content is divided into four modules:

Painting geometry: the main teaching projection basis; point, line and plane projection and the relationship between each other; three-dimensional projection; the intersection object; composite object; axis mapping and so on.

Basics of cartography: the main teaching standards related to the national standards; drawing tools and the use of instruments and techniques; a variety of engineering drawings and other methods of expression [5].

Professional map: the main teaching construction drawings; structural construction plans; equipment construction plans; road and bridge engineering drawings and other content.

AutoCAD computer graphics: the main teaching commonly used computer software functions; drawing principles; drawing methods; drawing techniques and the use of AutoCAD to draw all kinds of engineering drawings.

Reform the Traditional Teaching Methods. The traditional engineering graphics course is taught in the form of blackboard, supplemented by a certain amount of model display, in explaining the theory of projection. Although the blackboard is a better way to demonstrate, through the blackboard to the students demo projection the theoretical knowledge and how to draw the projection, to strengthen the interaction with the students, but the blackboard is not easy to display the image when draw cross lines, intersecting lines and other complex spatial relations, and teachers work manual drawing when the workload is very large, wasting time and efficiency relative to multimedia display is low, affecting the progress of the course. Therefore, in the engineering graphics course, take a combination of blackboard and multimedia teaching methods [6]. Combined with teaching materials to make lectures content made of multimedia courseware, so that the classroom density increased, teaching focused, teaching content lively and interesting. In the multimedia teaching, make full use of multimedia technology, with animation, video, pictures, text and other forms, the practice exercises, CAI courseware, network course system and other organic combination. Especially for descriptive geometry, in explaining the three-dimensional interception line, intersecting line concept and painting, through the image of the three-dimensional animation show, students can be in different perspectives dynamic observation of the various circumstances, carrying plaster model. As the multimedia form is diverse and illustrated, so that the difficult principles and methods of this courses become image and concrete, teaching content becomes image and intuitive, two-dimensional, three-dimensional animation simulation can greatly reduce the difficulty of learning, effective promote the teaching, so that students better grasp the content of this course [7-8]. The use of multimedia teaching can also save the writing time of the instructor, in the limited classroom time, the same class can teach more knowledge than before. 


\section{Results}

Improve the assessment method and teaching quality evaluation system for "descriptive geometry" part of the teaching content, the implementation of teaching and examination separation, test questions and manual questions both, unified examination, unified marking; and for "civil drawing and CAD" "drawing week" and some part of the teaching content evaluation, The examination is not equal to not test, the research group on the basis of in-depth research, combined with the reality, from the perspective of cultivating students comprehensive quality, the use of American operations scientist TLSaaty et al proposed analytic hierarchy process, the establishment of the corresponding mathematical model, content evaluation gives the level of total order of the consistent test results, access to the assessment of the quantitative index system, applied to teaching practice. The results show that the method is more accurate and fair to reflect the students 'grasp of teaching content and the quality of teachers' work attitude and teaching quality, and the method has good operability. The current teaching has adopted a new curriculum system, students in the combination of learning and training on the basis of open up the idea, to mobilize the initiative of learning, enthusiasm, cultivate the practical ability of engineering, the development of the spirit of continuous innovation. Teaching the use of our own editor of the teaching materials, exercises and matching multimedia courseware, achieved good results. As a result of the establishment of the curriculum assessment quality evaluation system, improve and reform the assessment method, the test results show that: the excellent rate of student test about $70 \%$, fill rate of about $5-10 \%$.

\section{Conclusions}

Through the survey of students and follow-up teachers, the practice has proved that curriculum reform has played a positive role in improving the quality of teaching. Students generally reflect that they have learned a lot after the end of the course study. The most important thing is that they think that their own mapping and drawing ability has been a good exercise; professional teachers think that the image of students thinking and innovation ability has greatly improved, and lay a good foundation of the follow-up professional courses and professional skills.

\section{References}

[1] J.X.Zhou: Journal of Shenyang Jianzhu University, Social Science Edition, Vol.2(2006), p.293295(In Chinese)

[2] J.X.Zhou: Civil Engineering Drawing (Chemical Industry Press, Beijing 2015, p42-48) (In Chinese)

[3] Yan Sun, Enterprise Research, Vol.7 (2013), p.175 (In Chinese)

[4] J.X.Zhou: Journal of Shenyang Jianzhu University, Social Science Edition, Vol.2 (2008), p.364366(In Chinese)

[5] S.Zhao: China Electric Power Education, Vol.11(2014), p.116-117(In Chinese)

[6] J.H.Ye: Journal of Luoyang Institute of Technology, Vol.9(2011), p.76-77(In Chinese)

[7] J.X.Zhou: Higher Education Research in China, Vol.2(2008), p.48-49(In Chinese)

[8] J.X.Zhou: Higher Education Research in China, Vol.2(2008), p.48-49(In Chinese) 